\title{
Asthma rehabilitation at high vs. low altitude: randomized parallel-group trial
}

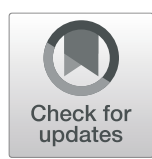

Stéphanie Saxer ${ }^{1,2}$, Simon R. Schneider ${ }^{1}$, Paula Appenzeller ${ }^{1}$, Patrick R. Bader ${ }^{1}$, Mona Lichtblau ${ }^{1}$, Michael Furian ${ }^{1}$, Ulan Sheraliev ${ }^{3}$, Bermet Estebesova ${ }^{3}$, Berik Emilov ${ }^{3}$, Talant Sooronbaev ${ }^{3}$, Konrad E. Bloch $^{1}$ and Silvia Ulrich ${ }^{1^{*}}$ (i)

\begin{abstract}
Background: To investigate the effect of asthma rehabilitation at high altitude (3100 m, HA) compared to low altitude (760 m, LA).

Methods: For this randomized parallel-group trial insufficiently controlled asthmatics (Asthma Control Questionnaire $(A C Q)>0.75$ ) were randomly assigned to 3-week in-hospital rehabilitation comprising education, physical-\&breathingexercises at LA or HA. Co-primary outcomes assessed at $760 \mathrm{~m}$ were between group changes in peak expiratory flow (PEF)-variability, and ACQ) from baseline to end-rehabilitation and 3 months thereafter.

Results: 50 asthmatics were randomized [median (quartiles) LA: ACQ 2.7(1.7;3.2), PEF-variability 19\%(14;33); HA: ACQ 2.0(1.6;3.0), PEF-variability 17\%(12;32)].

The LA-group improved PEF-variability by median(95\%Cl) -7\%(- 14 to $0, p=0.033), A C Q-1.4(-2.2$ to $-0.9, p<0.001)$, and after 3 months by $-3 \%(-18$ to $2, p=0.103)$ and $-0.9(-1.3$ to $-0.3, p=0.002)$. The HA-group improved PEFvariability by $-10 \%(-21$ to $-3, p=0.004)$, ACQ $-1.1(-1.3$ to $-0.7, p<0.001)$, and after 3 months by $-9 \%(-10$ to -3 , $p=0.003)$ and $-0.2(-0.9$ to $0.4, p=0.177)$. The additive effect of HA vs. LA directly after the rehabilitation on PEFvariability was $-6 \%(-14$ to 2$)$, on ACQ $0.3(-0.4$ to 1.1$)$ and after 3 months $-5 \%(-14$ to 5$)$ respectively $0.4(-0.4$ to 1.1$)$, all $p=$ NS.
\end{abstract}

Conclusion: Asthma rehabilitation is highly effective in improving asthma control in terms of PEF-variability and symptoms, both at LA and HA similarly.

Trial registration: Clinicaltrials.gov: NCT02741583, Registered April 18, 2016.

Keywords: Asthma, Pulmonary rehabilitation, Altitude

\section{Background}

Asthma is a major global health problem affecting over 300 million people worldwide with increasing prevalence in developing countries [1]. Asthma causes respiratory symptoms (mainly cough, dyspnea), limitation of activity and exacerbations that may require emergency treatment [1].

The current Global Initiative for Asthma (GINA) has outlined that patients with asthma should be managed, according to their level of asthma control, which includes symptoms during the day, symptoms during the

\footnotetext{
* Correspondence: silvia.ulrich@usz.ch

${ }^{1}$ Department of Pulmonology, UniversityHospital Zurich, Rämistrasse 100,

$\mathrm{CH}-8091$ Zurich, Switzerland

Full list of author information is available at the end of the article
}

night, use of reliever medication, limitation of daily activity, pulmonary function and exacerbations [1].

Many patients with asthma can be adequately controlled with bronchodilators in combination with inhaled corticosteroids. However, some asthma patient suffer from refractory disease despite medical therapy [2] and even controlled patients have to be prepared for flareups. Besides the pharmacological treatment, rehabilitation programs might be beneficial for asthma patients. The GINA guidelines state to advice all patients with chronic airflow disease for rehabilitation, whereas high altitude treatment has evidence level C [1].

Rehabilitation contains not only physical training and breathing exercises but also education, including smoking cessation $[3,4]$ aiming to deliver a profound insight

(C) The Author(s). 2019 Open Access This article is distributed under the terms of the Creative Commons Attribution 4.0 International License (http://creativecommons.org/licenses/by/4.0/), which permits unrestricted use, distribution, and 
into the disease and the ability to adequately react on exacerbations [5].

For decades, asthma patients have been sent to altitude clinics aiming to improve asthma control $[6,7]$. At high altitude there is less allergen exposure [8, 9], e.g. house dust mites do not exist $>1600 \mathrm{~m}$ above sea level (asl). A factor that might also mitigate a potential beneficial effect of altitude exposure on asthma control is the dry and generally less polluted air resulting in less inflammation $[10,11]$ and improved respiratory function [12]. In addition, the decreased air density at altitude leads to reduced airway resistance [13], which might additionally help to increase exercise capacity for asthmatics at altitude. The mountain environment may also signify less psychosocial stress for many patients having the opportunity to leave their everyday environment behind and enjoy a pleasant stay at altitude. Stress is associated with reduced sensitivity to endogenous glucocorticosteroids and chronic psychological stress has been associated with asthma exacerbation, whereas stress reduction seems to improve asthma control $[14,15]$.

Kyrgyzstan is a lower middle- income country with less access to advanced drug therapies [16]. Thus, allergen avoidance along with an intense asthma education and rehabilitation program is potentially of even greater importance in order to avoid disease exacerbations or chronification due to low asthma control.

As in the Swiss Alps, since many years asthma patients have been taken to Tuja Ashu, a high-altitude clinic located at $3100 \mathrm{~m}$ asl in the mountain area of the Kyrgyz Republic to improve asthma control. However, randomized controlled trials, which compare the effect of asthma rehabilitation at high compared to low altitude are completely lacking. Whether the reported positive effect of asthma rehabilitation at Alpine resorts is due to hypobaric hypoxic environment at altitude with less allergen exposure or due to the comprehensive rehabilitation program, including patient education and exercise or both is not clear to date.

We aimed to study a specific in-patient asthma rehabilitation program and its effectiveness on asthma control and investigated the effects of performing the rehabilitation at the Tuja Ashu high altitude clinic (HA), $3100 \mathrm{~m}$, in comparison to the same program performed at low altitude in Bishkek (LA), $760 \mathrm{~m}$. We hypothesized that a 3-week rehabilitation at high altitude improves PEF-variability and ACQ compared to a low altitude 3week rehabilitation. Additionally, we hypothesized the effects would be sustained at 3 months follow-up.

\section{Material and methods \\ Design}

In this randomized parallel-group trial asthmatics were assigned to in-patient rehabilitation either at LA (Bishkek, Kyrgyzstan, 760 m) or HA (Tuja Ashu, Kyrgyzstan, 3100 $\mathrm{m})$, between May and October 2016. The study was approved by the local Kyrgyz Ethics Committee (01-8/ 151) and the Ethics Committee Zurich (2016-00076).

\section{Participants}

Adults ( $\geq 18$ years) diagnosed with atopic (positive prick test) or non-atopic asthma according to the GINAguidelines were eligible if there disease was not well controlled, defined as asthma control questionnaire (ACQ) score $>0.75$ [17] and that have given written informed consent. Patients living permanently at $>1^{\prime} 000 \mathrm{~m}$ asl, heavy smokers ( $\geq 20$ cigarettes/day), patients with a history of acute mountain sickness (AMS) at altitudes $<3^{\prime}$ $100 \mathrm{~m}$, or with serious concomitant diseases (Additional file 1) were excluded. Study physicians recruited patients in the National Center for Cardiology and Internal Medicine in Bishkek (Kyrgyzstan).

\section{Intervention}

The 3-week rehabilitation program (for detailed description see Additional file 1) was identical for both groups and consisted of patient education, endurance training, muscle strength training, breathing exercises and guided walks (each $5 \mathrm{x} /$ week for $30-45 \mathrm{~min}$ and a total duration of $5 \mathrm{~h}$ /day). All patients received an asthma action plan containing instructions on recognition of worsening asthma control and on suggested actions [1]. Patients from the HA group were transferred via minibus, to the high altitude clinic and back to Bishkek, respectively.

\section{Outcomes}

All outcomes were assessed at $760 \mathrm{~m}$ asl.

The co-primary outcomes were the differences of the changes between the two groups (LA vs. HA) in the score of the ACQ and the PEF-variability from baseline to the end of the 3-week rehabilitation and to 3-month follow-up (FU). The PEF-variability was computed as [(day's highest-day's lowest)/mean of day's highest+lowest] [1]. PEF measures were made four times daily.

Secondary outcomes were the percentage of patients with well controlled or partially controlled asthma (ACQ score $<1.5$ ), the between-group differences of the change in the following assessments to end of rehabilitation and FU: forced expiratory volume in $1 \mathrm{~s}$ (FEV1), PEF-variability, asthma-related quality of life (AQLQ), generic quality of life assessed by the short-form 36 questionnaire (SF-36), exercise performance assessed by the sit-to-stand (STS), 6 min walking distance (6MWD), airway inflammation assessed by the exhaled nitric oxide (FeNO) [18] and blood eosinophils and hemoglobin concentration.

The HA-group additionally filled out the Environmental Symptom Questionnaire cerebral score (AMS-c) at the second day at altitude to assess safety of altitude exposure symptoms of acute mountain sickness [19]. 


\section{Sample size estimation}

With an estimated standard deviation of the ACQ-score of 1 [7] and a minimal clinical important difference of 0.5 [20], 16 patients needed to be included per group to achieve a power of 0.8 with an alpha of 0.05 . For the same power of the co-primary endpoint PEF-variability, we assumed a difference of $3 \%$ in PEF-variability with a standard deviation of $3 \%$ between the groups again indicating 16 patients. Thus, to account for drop-outs, we aimed to include at least 20 patients per group.

A list of the eligible patients was sent to an independent coordinator who randomly allocated patients to rehabilitation at LA or HA by a computer program (Stata 14.0, StataCorp, College Station, Texas, USA) with the plugin "rct_minim") providing minimisation with regard to atopy [21]. Blinding of the intervention (rehabilitation and altitude) was intrinsically not possible.

\section{Data analysis}

The analysis was performed on data from all participants undergoing rehabilitation at one of the two locations. Data are summarized as median (interquartile range, IQR). The primary and secondary outcomes were evaluated with the Wilcoxon test for paired samples within group and the Mann-Whitney-U-Test for the difference between groups. Difference between the change in PEF-variability and change in ACQ from baseline to 3 weeks and from baseline to 3 months follow-up were calculated and presented as median differences with $95 \%$ confidence intervals. A $p<0.05$ was considered statistically significant.

Linear regression analysis was used to estimate the effect of the patients' characteristics on the change of the PEF-variability. Statistical analyses were conducted with SPSS 22 (SPSS, Chicago, Illinois, USA).

\section{Data reporting}

The data is reported in adherence with the CONSORT guidelines.

\section{Results}

Of 159 eligible patients 50 were included in the study: 25 per group with one patient in each group not receiving the intervention (one for professional and one family reasons), see study flow chart Fig. 1. Therefore, the analysis was performed per protocol on data from all participants undergoing rehabilitation. Baseline characteristics are shown in Table 1.

\section{Primary outcomes}

At baseline, the elevated values of ACQ and PEF-variability confirmed that the asthma was poorly controlled according to selection criteria. Both outcomes significantly improved during the 3-week rehabilitation program at LA although PEF-variability was reduced to below $10 \%$ in the HA-group only. After 3 months, the improvements in ACQ were maintained in both groups while PEF-variability remained significantly below baseline and below $10 \%$ in the HA-

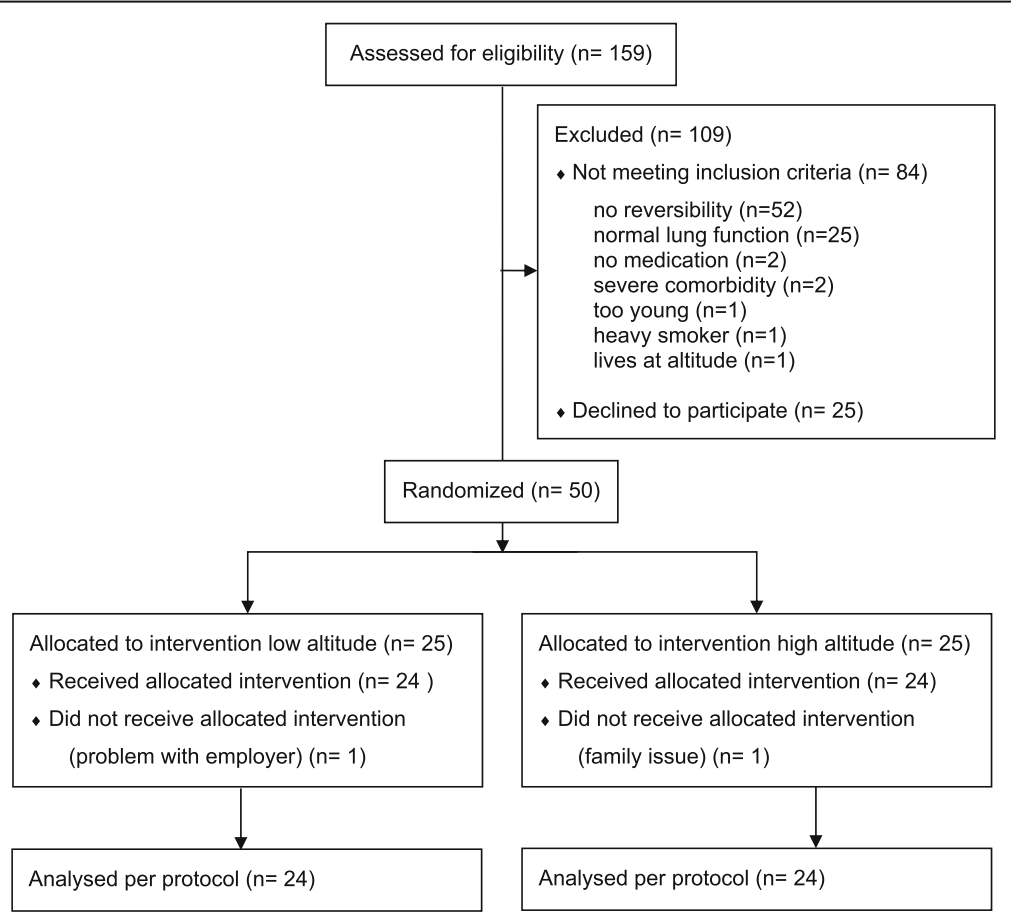

Fig. 1 Study flow chart 
Table 1 Baseline characteristics

\begin{tabular}{lll}
\hline & Low altitude $(760 \mathrm{~m})$ rehabilitation group & High altitude $(3100 \mathrm{~m})$ rehabilitation group \\
\hline Number of participants (Females) & $25(18,72 \%)$ & $25(16,64 \%)$ \\
Age, years & $47(34 ; 53)$ & $43(33 ; 49)$ \\
Body mass index, $\mathrm{kg} / \mathrm{m}^{2}$ & $24(23 ; 27)$ & $26(23 ; 29)$ \\
Non-smokers, $n(\%)$ & $25(100)$ & $25(100)$ \\
Atopy, $n(\%)$ & $23(92)$ & $23(92)$ \\
Peak expiratory flow, L/min & $311(274 ; 378)$ & $326(261 ; 368)$ \\
FeNO, ppb & $37(26 ; 46)$ & $51(37 ; 73)$ \\
\hline
\end{tabular}

Note: Data are given as median (quartiles) or numbers (\%)

Abbreviations: FeNO exhaled nitric oxid

group only. Moreover, the absolute values of PEFvariability at 3 weeks and 3 months were lower in the HAgroup compared to the LA-group. There was no significant difference between groups (HA vs. LA) with regard to the changes of the ACQ and the PEF-variability from baseline to end of rehabilitation at 3 weeks and FU at 3 months (Table 2 and Figs. 2, 3).

\section{Secondary outcomes}

The percentage of patients with well controlled or partly controlled asthma (ACQ < 1.5) [17] increased in the LAgroup from 20 , to $83 \%(p<0.001)$ after the rehabilitation and to $54 \%(p=0.003)$ at 3 months; corresponding values in the HA-group were $16,71 \%(p<0.001)$ and $48 \%(p=$ $0.008)$ respectively).

At the end of the 3-week rehabilitation almost all secondary outcomes, including the 6MWD, STS, lung function and quality of life assessed at $760 \mathrm{~m}$ significantly improved in both groups (Tables 3 and 4). Asthma control measured by the use of reliever medication (ACQ question number 6) significantly improved with rehabilitation (LA $p=0.025$, HA $p=0.002$ ) and to a similar extent in both groups (Additional file 1: Table S1).

We found that the sit-to-stand test and the FeNO improved significantly more in the HA-group compared to the LA-group. Median changes of other secondary outcomes assessed before and after the 3-week rehabilitation at $760 \mathrm{~m}$ were similar at LA or HA (Table 3). Improvements of secondary outcomes were mostly maintained at the follow-up assessment at 3 months. The changed of the STS remained higher in the HA compared to LA.

Furthermore, the HA-group significantly increased the hemoglobin concentration compared to the LA-group from baseline to week 3 [median difference 7 (4 to 11) $\mathrm{g} / \mathrm{L}, p>0.001]$.

Linear regression analysis (Table 5) revealed that the PEF-variability before the rehabilitation program and the rehabilitation at HA vs. LA were independent predictors of the improvement in PEF-variability $[\triangle \mathrm{PEF}$-variability (baseline-end rehabilitation) $=-0.375+0.914$ (baseline PEF-variability) + 0.091(Group); $\left.\mathrm{R}^{2} 0.666, p<0.001\right]$.

\section{Adverse events and safety measures}

Of the 25 patients undergoing rehabilitation at HA, symptoms of AMS defined as score $\geq 0.7$ were present in 11 patients in Bishkek $(760 \mathrm{~m})$ and 6 patients at altitude with only two having a higher score at HA. One patient needed medical treatment for an AMS with severe headache and a very high AMS score of 4.46.

During the rehabilitation program the following events occurred, which were not directly linked to the training:

Table 2 Primary endpoints assessed at low altitude $(760 \mathrm{~m})$

\begin{tabular}{|c|c|c|c|c|c|c|c|c|}
\hline & \multicolumn{3}{|c|}{ Low altitude rehabilitation group } & \multicolumn{3}{|c|}{ High altitude rehabilitation group } & \multirow{2}{*}{$\begin{array}{l}\text { Between group } \\
\text { difference of } \\
\text { changes from } \\
\text { BL to } 3 \text { weeks }\end{array}$} & \multirow{2}{*}{$\begin{array}{l}\text { Between group } \\
\text { difference of } \\
\text { changes from } \\
\text { BL to } 3 \text { months }\end{array}$} \\
\hline & Baseline & $\begin{array}{l}\text { End of rehabilitation } \\
\text { ( } 3 \text { weeks) }\end{array}$ & $\begin{array}{l}\text { Follow-up } \\
\text { (3 months) }\end{array}$ & Baseline & $\begin{array}{l}\text { End of rehabilitation } \\
\text { ( } 3 \text { weeks) }\end{array}$ & $\begin{array}{l}\text { Follow-up } \\
\text { (3 months) }\end{array}$ & & \\
\hline PEF-Var. & $19(14 ; 33)$ & $15(8 ; 23)$ & $15(9 ; 24)$ & $17(12 ; 32)$ & $6(4 ; 9) \#$ & $8(5 ; 14) \#$ & & \\
\hline change & & $\begin{array}{l}-7.4(-13.9 \\
\text { to } 0)^{*}\end{array}$ & $\begin{array}{l}-2.5(-17.5 \\
\text { to } 2.1)\end{array}$ & & $\begin{array}{l}-10.4(-21.3 \\
\text { to }-3.4)^{* *}\end{array}$ & $\begin{array}{l}-8.9(-10.3 \\
\text { to }-2.8)^{* *}\end{array}$ & $\begin{array}{l}-5.8(-14 \\
\text { to } 2)\end{array}$ & $\begin{array}{l}-5(-13.6 \\
\text { to } 5.0)\end{array}$ \\
\hline ACQ & $\begin{array}{l}2.7 \\
(1.7 ; 3.2)\end{array}$ & $0.8(0.4 ; 1.6)$ & $1.4(0.9 ; 2.1)$ & $\begin{array}{l}2.0 \\
(1.6 ; 3.0)\end{array}$ & $0.9(0.4 ; 1.6)$ & $1.6(0.9 ; 3.0)$ & & \\
\hline change & & $\begin{array}{l}-1.4(-2.2 \\
\text { to }-0.9)^{* * *}\end{array}$ & $\begin{array}{l}-0.9(-1.3 \\
\text { to }-0.3)^{* *}\end{array}$ & & $\begin{array}{l}-1.1(-1.3 \\
\text { to }-0.7)^{* * *}\end{array}$ & $\begin{array}{l}-0.2(-0.9 \\
\text { to } 0.4)\end{array}$ & $\begin{array}{l}0.3(-0.4 \\
\text { to } 1.1)\end{array}$ & $\begin{array}{l}0.4(-0.4 \\
\text { to } 1.1)\end{array}$ \\
\hline
\end{tabular}

Note: Data are given as median (quartiles) and median difference (confidence interval)

Abbreviations: PEF-Var. Peak-flow variability, \%, ACQ Asthma Control questionnaire. ${ }^{*}: p<0.05$; ${ }^{* *}: p<0.01$; ${ }^{* * *}$ : $p<0.001$ tested with Wilcoxon test for paired samples (baseline vs. 3 weeks follow up and baseline vs. 3 months follow up). \#: $p<0.05$ vs. low altitude group 


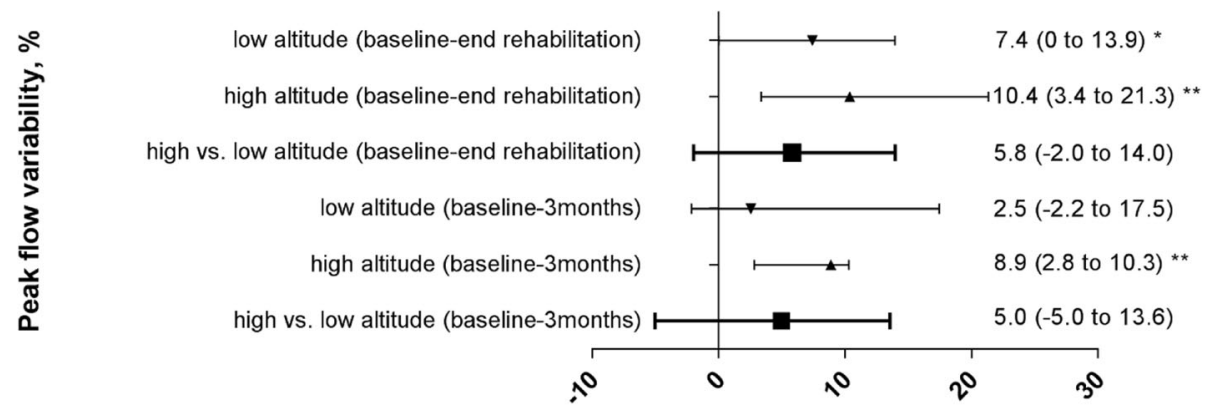

Fig. 2 Peak flow variability of both groups, median changes (95\%Cl) from baseline to end rehabilitation after 3 weeks and 3 months follow up and median differences $(95 \% \mathrm{Cl})$ between groups

In the LA rehabilitation group, one patient had a slight cold, one had temporary fever and one had a sore throat; in the HA one patient was treated with acetazolamide for 1 day for relevant AMS (including headache), one had slight headache, one had intermittent diarrhea and one had an asthma exacerbation defined as a decline in PEF of $>12 \%$. None of the patient had to interrupt the whole rehabilitation program for $>1$ day due to symptoms.

\section{Discussion}

This is the first randomized controlled trial which investigated the additional effect of undergoing a 3-week rehabilitation program at $\mathrm{HA}(3100 \mathrm{~m})$ vs. LA $(760 \mathrm{~m})$ on asthma control in patients with uncontrolled asthma. We found that a comprehensive 3-week rehabilitation program including education, endurance training, muscle- and breathing exercise significantly improved asthma control both at low and high altitude. The effect of the rehabilitation at HA was not superior compared to the same rehabilitation program at LA in ameliorating asthma control as assessed by the ACQ and PEFvariability. Nevertheless, rehabilitation at $\mathrm{HA}$ was well tolerated and led to a better improvement of exercise capacity (STS) and airway inflammation assessed by
FeNO. In addition, regression analysis revealed that the overall improvement in PEF-variability from baseline to 3 weeks was better in the HA vs. LA-group when controlling for relevant confounders such as age, gender and the baseline absolute PEF. Thus suggesting that patients with a higher baseline PEF-variability may benefit more from a rehabilitation at altitude.

For many years, asthma patients are taken to HA in order to improve their asthma control in a presumptively cleaner environment with less allergen exposure. The effect of training at altitude ( $1600 \mathrm{~m}$ asl) on asthma control was investigated in a prospective, uncontrolled study by Rijssenbeek-Nouwens and coworkers [7], which showed that sensitized and unsensitized patients improved their ACQ score by 1.4 and 1.5 after 12 weeks. However, as this study was lacking a low-altitude control group, it remains unclear whether the favorable effect was due to altitude exposure or the educational and exercise training per se.

In the present randomized trial, we could not show an additive effect of providing the rehabilitation at HA vs. LA on our primary outcome. This extends data from a previous non-randomized study suggesting that that allergen avoidance during HA sojourns improved bronchial hyperresponsiveness in adolescents with severe

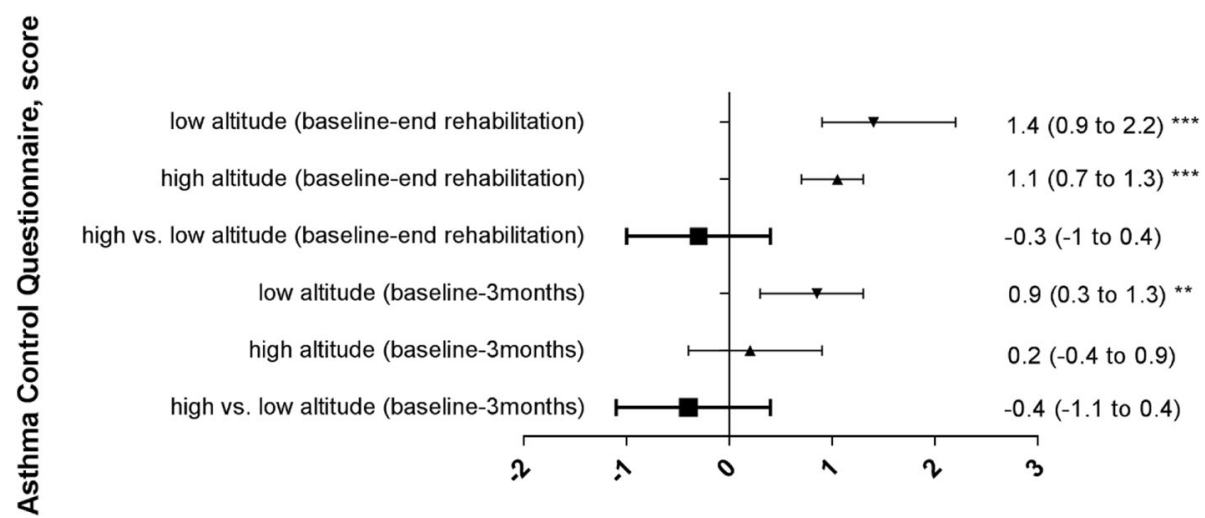

Fig. 3 Asthma control of both groups, median changes (95\%Cl) from baseline to end rehabilitation after 3 weeks and 3 months follow up and median differences $(95 \% \mathrm{Cl})$ between groups 
Table 3 Secondary endpoints

\begin{tabular}{|c|c|c|c|c|c|c|c|c|}
\hline & \multicolumn{3}{|l|}{ Low altitude } & \multicolumn{3}{|c|}{ High altitude } & \multirow{2}{*}{$\begin{array}{l}\text { Between group } \\
\text { difference of } \\
\text { changes from } \\
\text { BL to } 3 \text { weeks }\end{array}$} & \multirow{2}{*}{$\begin{array}{l}\text { Between group } \\
\text { difference of } \\
\text { changes from } \\
\text { BL to } 3 \text { months }\end{array}$} \\
\hline & Baseline & $\begin{array}{l}\text { End of } \\
\text { rehabilitation } \\
\text { ( } 3 \text { weeks) }\end{array}$ & $\begin{array}{l}\text { Follow-up } \\
\text { (3 months) }\end{array}$ & Baseline & $\begin{array}{l}\text { End of } \\
\text { rehabilitation } \\
\text { ( } 3 \text { weeks) }\end{array}$ & $\begin{array}{l}\text { Follow-up } \\
\text { (3 months) }\end{array}$ & & \\
\hline FEV1, \%pred. & $61(42 ; 77)$ & $96(54 ; 80)^{*}$ & $71(58 ; 83)^{*}$ & $64(59 ; 71)$ & $78(67 ; 83)^{* * *}$ & $72(58 ; 85)^{*}$ & $\begin{array}{l}3.6(-4.9 \text { to } \\
10.9)\end{array}$ & $1.7(-7.3$ to 9.6$)$ \\
\hline FVC, \%pred. & $83(63 ; 93)$ & $87(79 ; 96)^{*}$ & $87(77 ; 94)$ & $82(74 ; 92)$ & $91(83 ; 98)^{* *}$ & $84(78 ; 95)$ & $\begin{array}{l}1.5(-5.5 \text { to } \\
10.2)\end{array}$ & $-.45(-7.0$ to 6.1$)$ \\
\hline FEV1/ FVC, pre & $.63(.52 ; .69)$ & $.63(.53 ; .70)$ & $.67(.54 ; .70)^{*}$ & $.67(.59 ; .71)$ & $.70(.63 ; 75)^{* * *}$ & $.69(.6 ; 75)^{* *}$ & .01 (-.03 to .05$)$ & $.01(-.04$ to .06$)$ \\
\hline $6 \mathrm{MWD}, \mathrm{m}$ & $\begin{array}{l}490(452 ; \\
510)\end{array}$ & $\begin{array}{l}521(493 \\
549)^{* * *}\end{array}$ & $\begin{array}{l}504(486 ; \\
536)^{*}\end{array}$ & $\begin{array}{l}536(491 ; \\
571)\end{array}$ & $571(522 ; 624)^{* *}$ & $\begin{array}{l}570(517 ; \\
607)\end{array}$ & -2 (-24 to 22$)$ & $4(-26$ to 31$)$ \\
\hline STS, repetitions & $21(19 ; 24)$ & $24(21 ; 26)^{* *}$ & $25(22 ; 28)^{* *}$ & $25(23 ; 28)$ & $36(30 ; 40)^{* * *}$ & $30(27 ; 39)^{* * *}$ & 7 (4 to 11$)$ & $4(0$ to 7$)$ \\
\hline FeNO, ppb & $37(25 ; 58)$ & $19(36 ; 51)$ & - & $51(35 ; 76)$ & $27(23 ; 52)^{* *}$ & - & $-18(-36$ to 0$)$ & \\
\hline $\begin{array}{l}\text { Hemoglobin, } \\
\text { g/l }\end{array}$ & $\begin{array}{l}139(131 ; \\
150)\end{array}$ & $139(125 ; 145)$ & & $\begin{array}{l}142(127 ; \\
158)\end{array}$ & $145(138 ; 166)$ & & 7 (4 to 11$)$ & \\
\hline EOS, $10 \wedge 9 / 1$ & $.39(.28 ; .63)$ & $.31(.18 ; .57)$ & & $.38(.28 ; .57)$ & $.26(.18 ; .45)$ & & $\begin{array}{l}-.05(-.16 \text { to } \\
.04)\end{array}$ & \\
\hline EOS, \% & $6.3(5.0 ; 9.3)$ & $5.4(2.7 ; 7.1)^{*}$ & - & $6.2(5.1 ; 8.6)$ & $3.9(2.4 ; 6.5)^{* * *}$ & - & $\begin{array}{l}-1.1(-2.6 \text { to } \\
0.5)\end{array}$ & \\
\hline
\end{tabular}

Note: Data are given as median (quartiles) and median difference (confidence interval)

Abbreviations: FEV1 forced expiratory volume in $1 \mathrm{~s}$, FVC forced vital capacity, 6MWD 6 min walking distance, STS Sit-to-stand, FeNO exhaled nitric oxid, EOS blood eosinophils

${ }^{*}: p<0.05 ;{ }^{* *}: p<0.01 ;{ }^{* * *}: p<0.001$ tested with Wilcoxon test for paired samples (baseline vs. 3 week follow up and baseline vs. 3 months follow up); bold: significant between group differences

asthma [6]. Additional benefits of HA than mere allergen reduction have been postulated such as dryer, thinner and cleaner air, less fungi and an increased vitamin$\mathrm{D}$ production due to increased exposure to sunlight [8].

In our study, the vast majority of participants $(92 \%)$ had atopic asthma, but the improvements found with the rehabilitation at HA were similar as with the same program performed at LA. Nevertheless, we found a significantly greater reduction of $\mathrm{FeNO}$ in patients undergoing HA- vs. LA rehabilitation. This may point towards less airway inflammation in the HA-group. The findings are especially remarkable as FeNO measurements were performed at $760 \mathrm{~m}$ on the day after return from HA presumably when patients were already re-exposed to some allergens and other noxious stimuli. Our data are in line with previous reports of beneficial effects of HA rehabilitation in adults and children on FeNO and asthma control in both, allergic and non-allergic asthmatics according to nonrandomized studies [7, 11, 22].

Several randomized trials showed a positive impact of physical exercise and training on asthma control [5, 23-25] and maximal performance but no improvements in lung function [26]. Our study confirmed that a 3-week comprehensive rehabilitation program at both low and high

Table 4 Effect of HA and LA rehabilitation on Quality of Life

\begin{tabular}{|c|c|c|c|c|c|c|c|c|}
\hline & \multicolumn{3}{|l|}{ Low altitude } & \multicolumn{3}{|c|}{ High altitude } & \multirow[b]{2}{*}{$\begin{array}{l}\text { Between group } \\
\text { difference of } \\
\text { change } B L-3 w\end{array}$} & \multirow[b]{2}{*}{$\begin{array}{l}\text { Between group } \\
\text { difference of } \\
\text { change } B L-3 \mathrm{~m}\end{array}$} \\
\hline & Baseline & $\begin{array}{l}\text { End of } \\
\text { rehabilitation } \\
\text { ( } 3 \text { weeks) }\end{array}$ & $\begin{array}{l}\text { Follow-up } \\
\text { (3 months) }\end{array}$ & Baseline & $\begin{array}{l}\text { End of } \\
\text { rehabilitation } \\
\text { ( } 3 \text { weeks) }\end{array}$ & $\begin{array}{l}\text { Follow-up } \\
\text { (3 months) }\end{array}$ & & \\
\hline AQLQ Score & $3.6(3.1 ; 4.8)$ & $5.5(4.4 ; 6.4)^{* * *}$ & $5.1(3.8 ; 5.9)^{* * *}$ & $3.9(3.1 ; 4.6)$ & $5.6(4.4 ; 6.3)^{* * *}$ & $4.9(3.5 ; 6.2)^{*}$ & $-.0(-.7$ to .8$)$ & $-.5(-1.6$ to .3$)$ \\
\hline AQLQ Activity limitation & $4.3(3.5 ; 5.1)$ & $5.7(4.4 ; 6.3)^{* *}$ & $5.0(4.3 ; 5.9)^{* * *}$ & $4.4(3.5 ; 5.0)$ & $5.9(4.8 ; 6.4)^{* * *}$ & $5.0(3.8 ; 6.4)^{* *}$ & $.0(-.7$ to .7$)$ & $-.1(-.7$ to .6$)$ \\
\hline AQLQ Symptoms & $3.8(3.3 ; 4.9)$ & $6.0(4.9 ; 6.5)^{* * *}$ & $5.5(4.0 ; 6.0)^{* *}$ & $3.7(3.1 ; 4.8)$ & $5.4(4.4 ; 6.6)^{* * *}$ & $5.5(3.2 ; 6.5)^{*}$ & $-.2(-1$ to .7$)$ & $-.5(-1.9$ to .4$)$ \\
\hline AQLQ Emotional function & $3.4(2.5 ; 4.5)$ & $5.0(4.1 ; 6.0)^{* *}$ & $4.7(3.7 ; 6.4)^{* * *}$ & $3.6(2.7 ; 4.6)$ & $5.3(3.8 ; 6.6)^{* * *}$ & $4.8(2.8 ; 6.0)^{* *}$ & $.0(-.8$ to .8$)$ & $-.4(-1.4$ to .4$)$ \\
\hline $\begin{array}{l}\text { AQLQ Environ-mental } \\
\text { stimuli }\end{array}$ & $3.3(2.1 ; 4.0)$ & $5.0(3.2 ; 6.2)^{* *}$ & $4.3(3.3 ; 5.5)^{* *}$ & $3.0(2.6 ; 4.5)$ & $5.0(4.6 ; 5.9)^{* * *}$ & $4.6(3.0 ; 5.7)^{* *}$ & $.0(-1$ to .8$)$ & $.0(-1$ to .8$)$ \\
\hline$S F-36, P C S$ & $40(35 ; 43)$ & $40(36 ; 46)$ & $42(36 ; 47)$ & $50(43 ; 54)$ & $46(38 ; 52)$ & $51(45 ; 54)$ & $-3(-10$ to 3$)$ & $-1(-5$ to 4$)$ \\
\hline$S F-36, M C S$ & $44(36 ; 49)$ & $41(34 ; 48)$ & $44(36 ; 50)$ & $51(47 ; 56)$ & $48(41 ; 55)$ & $58(56 ; 61)$ & $-3(-12$ to 5$)$ & $5(-2$ to 11$)$ \\
\hline
\end{tabular}

Note: Data are given as median (quartiles) and median difference (confidence interval)

Abbreviations: AQLQ Asthma Quality of Life Questionnaire, SF-36 Short-form 36, PCS Physical component score, MCS mental summary score

${ }^{*}: p<0.05 ;{ }^{* *}: p<0.01 ;{ }^{* * *}: p<0.001$ tested with Wilcoxon test for paired samples (baseline vs. 3 week follow up and baseline vs. 3 months follow up) 
Table 5 Regression analysis

\begin{tabular}{llll}
\hline $\begin{array}{l}\text { Dependent variable }=\Delta \text { Peak } \\
\text { flow variability pre-post } \\
\text { rehabilitation }\end{array}$ & \multicolumn{3}{l}{ Multivariable analysis } \\
\cline { 2 - 4 } Geefficient & $95 \% \mathrm{Cl}$ & $p$ \\
\hline Gender (male =1, female =2) & .025 & -.030 to .079 & .371 \\
Age, years & .002 & -.001 to .004 & .160 \\
Group, $(\mathrm{LA}=1 / \mathrm{HA}=2)$ & .091 & .042 to .140 & .001 \\
Peak flow variability, \% baseline & .914 & .718 to 1.111 & .000 \\
Peak flow, ml baseline & .011 & -.006 to .029 & .195 \\
Intercept & -.375 & -.607 to -.143 & .002 \\
\hline
\end{tabular}

Note: $n=48$. $\mathrm{R}^{2}$ was $0.666, p<0.001$. $\mathrm{Cl}=$ confidence interval

Abbreviations: $L A$ low altitude, $H A$ high altitude

altitude was highly effective to render sustained improvements in asthma control, quality of life and exercise capacity directly after the rehabilitation and up to 3 months.

We could show that exercise capacity assessed by the 6MWD and the STS improved significantly with our comprehensive 3-week rehabilitation program and the improvements were maintained up to 3 months followup, potentially due to the continuation of daily exercise according to the programs instruction in this highly motivated asthma collective. The improvement in exercise capacity found in both our groups where slightly smaller compared to other studies, assumedly because the rehabilitation lasted 3 weeks compared to 12 weeks [7]. Another study with a 12-week rehabilitation program at low altitude increased the exercise capacity in terms of the $\mathrm{VO}_{2}$ max and the total treadmill time [27]. Whereas the improvements in 6MWD were similar in the group that trained at HA vs. LA, we found a better improvement of the STS test in the HA vs. LA-group. This may point towards a higher effect of training at HA on exercise performance after return to LA. Such beneficial effects of altitude training have been previously described for many athletes and HA-training has been incorporated in training plans due to its increase in hemoglobin and thus oxygen transport [28]. Of interest, the additive effect of HA rehabilitation on the STS were maintained up to 3 months and might be at least partly explained by a significant increase in hemoglobin in the HA-group.

The significant improvement of asthma specific quality of life reflects an important effect of rehabilitation that was achieved to a similar degree in the HA and LA group. Also all sub scores of the AQLQ improved after the rehabilitation and remained at this level at 3 months follow up in both groups without difference between groups.

The program was well tolerated by patients at both locations, expect one patient at altitude who suffered from mild AMS (headache), no adverse events occurred. Intrinsically, it was not possible to blind investigators and patients to the intervention, and thus other factors than altitude and rehabilitation such as being away from home or factors concerning comfort might have played a role in the outcomes. However, this would be the case with any rehabilitation program all over the world. Among the participants of our study, there were no current smokers. Thus, our results may not be transferable to smoking asthmatics. The current study population revealed a relatively low and thus favorable daily PEF-variability and it may well be that the effect of a rehabilitation program including education and training would have been different, potentially even better, in a more compromised asthma collective. Despite these limitations, this study is of particular importance because of its robust design as a randomize trial.

\section{Conclusion}

In the present randomized trial, we could show that a 3week comprehensive asthma rehabilitation program including a clear action plan, peak flow diary, patient education, respiratory exercises, force and endurance training is highly effective in sustainably improving asthma control in terms of the Co-primary outcome asthma-related quality of life (ACQ) and PEF-variability, but also exercise performance and this positive effect was irrespective of the altitude is the rehabilitation program was performed.

\section{Additional file}

Additional file 1: Asthma rehabilitation at high vs. low altitude: randomized controlled parallel-group trial. (DOCX $32 \mathrm{~kb}$ )

\section{Abbreviations}

6MWD: 6 min walking distance; ACQ: Asthma Control Questionnaire; AMSc: Environmental Symptom Questionnaire cerebral score; AQLQ: Asthmarelated quality of life questionnaire; asl: above sea level; FeNO: Exhaled nitric oxide; FEV1: Forced expiratory volume in $1 \mathrm{~s}$; FU: Follow-up; GINA: Global Initiative for Asthma; HA: High altitude; IQR: Interquartile range; LA: Low altitude; PEF: Peak expiratory flow; SF-36: Short-form 36 questionnaire; STS: Sit-to-stand

\section{Acknowledgements}

We acknowledge the Kyrgyz staff including physicians and nurses etc. who supported us to conduct this study.

\section{Authors' contribution}

All authors contributed significantly to the submitted work. SU, KEB, TS, SRS and SS contributed to the conception and design of the study, the collection, analysis and interpretation of data, and the writing of the manuscript. SU is the guarantor of the paper. SS, SRS, PA, PRB, ML, MF, US, $\mathrm{BE} 1, \mathrm{BE} 2, \mathrm{TS}, \mathrm{KEB}$ and contributed to data collection and critically revised the manuscript. All authors gave their final approval.

\section{Funding}

The study was funded by the Zurich Lung League and the Swiss National Science Foundation.

\section{Availability of data and materials}

The datasets used and/or analysed during the current study are available from the corresponding author on reasonable request.

\section{Competing interest}

SU reports grants from Zurich Lung League, grants from Swiss National Science Foundation, during the conduct of the study; grants and personal fees from Actelion SA, personal fees from Bayer SA, personal fees from MSD, 
grants and personal fees from Orpha Swiss, outside the submitted work. KEB reports grants from Zurich Lung League, grants from Swiss National Science Foundation, during the conduct of the study. SS, SRS, PA, PRB, ML, MF, US, $\mathrm{BE}, \mathrm{BEm}$ and TS have nothing to declare.

\section{Ethics approval and consent to participate}

The study was approved by the local Kyrgyz Ethics Committee (01-8/151) and the Ethics Committee Zurich (2016-00076). All patients have given written informed consent.

\section{Author details}

'Department of Pulmonology, UniversityHospital Zurich, Rämistrasse 100, CH-8091 Zurich, Switzerland. 'Department of Health Sciences \& Health Policy, University of Lucerne, Lucerne, Switzerland. ${ }^{3}$ National Center for Cardiology and Internal Medicine, Bishkek, Kyrgyzstan.

Received: 21 September 2018 Accepted: 2 July 2019

Published online: 24 July 2019

\section{References}

1. Global Initiative for Asthma Scientific C. Global Strategy for Asthma Management and Prevention 2017 Available from: https://ginasthma.org/ wp-content/uploads/2019/04/wmsGINA-2017-main-report-final_V2.pdf.

2. Bel EH, Sousa A, Fleming L, Bush A, Chung KF, Versnel J, et al. Diagnosis and definition of severe refractory asthma: an international consensus statement from the innovative medicine initiative (IMI). Thorax. 2011:66(10):910-7.

3. Gibson PG, Powell H, Coughlan J, Wilson AJ, Abramson M, Haywood P, et al. Self-management education and regular practitioner review for adults with asthma. Cochrane Database Syst Rev. 2003;(1):CD001117. https://www.ncbi. nlm.nih.gov/pubmed/12535399.

4. Powell H, Gibson PG. Options for self-management education for adults with asthma. Cochrane Database Syst Rev. 2003;(1):CD004107. https://www. ncbi.nlm.nih.gov/pubmed/12535511.

5. Nathell L. Effects on sick leave of an inpatient rehabilitation programme for asthmatics in a randomized trial. Scand J Public Health. 2005:33(1):57-64.

6. Grootendorst DC, Dahlen SE, Van Den Bos JW, Duiverman EJ, Veselic-Charvat $M$, Vrijlandt EJ, et al. Benefits of high altitude allergen avoidance in atopic adolescents with moderate to severe asthma, over and above treatment with high dose inhaled steroids. Clin Exp Allergy. 2001;31(3):400-8.

7. Rijssenbeek-Nouwens LH, Fieten KB, Bron AO, Hashimoto S, Bel EH, Weersink EJ. High-altitude treatment in atopic and nonatopic patients with severe asthma. Eur Respir J. 2012;40(6):1374-80.

8. Rijssenbeek-Nouwens LH, Bel EH. High-altitude treatment: a therapeutic option for patients with severe, refractory asthma? Clin Exp Allergy. 2011; 41(6):775-82.

9. Spieksma FT, Zuidema P, Leupen MJ. High altitude and house-dust mites. Br Med J. 1971;1(5740):82-4.

10. Platts-Mills TA, Chapman MD. Dust mites: immunology, allergic disease, and environmental control. J Allergy Clin Immunol. 1987:80(6):755-75.

11. Karagiannidis C, Hense G, Rueckert B, Mantel PY, Ichters B, Blaser K, et al. High-altitude climate therapy reduces local airway inflammation and modulates lymphocyte activation. Scand J Immunol. 2006;63(4):304-10.

12. Renzetti G, Silvestre G, D'Amario C, Bottini E, Gloria-Bottini F, Bottini N, et al. Less air pollution leads to rapid reduction of airway inflammation and improved airway function in asthmatic children. Pediatrics. 2009;123(3): 1051-8

13. Skloot G, Permutt S, Togias A. Airway hyperresponsiveness in asthma: a problem of limited smooth muscle relaxation with inspiration. J Clin Invest. 1995:96(5):2393-403.

14. Haczku A, Panettieri RA Jr. Social stress and asthma: the role of corticosteroid insensitivity. J Allergy Clin Immunol. 2010;125(3):550-8.

15. Bosley CM, Corden ZM, Cochrane GM. Psychosocial factors and asthma. Respir Med. 1996;90(8):453-7.

16. WHO. Ambient air pollution: a global assessment of exposure and burden of disease. Geneva: Department of Public Health, Environmental and Socia Determinants of Health (PHE) World Health Organization; 2016. Available from: http://apps.who.int/iris/bitstream/10665/250141/1/9789241511353eng.pdf

17. Juniper EF, Bousquet J, Abetz L, Bateman ED, Committee G. Identifying 'well-controlled' and 'not well-controlled' asthma using the asthma control questionnaire. Respir Med. 2006;100(4):616-21.
18. Dweik RA, Boggs PB, Erzurum SC, Irvin CG, Leigh MW, Lundberg JO, et al. An official ATS clinical practice guideline: interpretation of exhaled nitric oxide levels (FENO) for clinical applications. Am J Respir Crit Care Med. 2011;184(5):602-15.

19. Sampson JB, Cymerman A, Burse RL, Maher JT, Rock PB. Procedures for the measurement of acute mountain sickness. Aviat Space Environ Med. 1983; 54(12 Pt 1):1063-73.

20. Bateman ED, Esser D, Chirila C, Fernandez M, Fowler A, Moroni-Zentgraf $P$, et al. Magnitude of effect of asthma treatments on asthma quality of life questionnaire and asthma control questionnaire scores: systematic review and network meta-analysis. J Allergy Clin Immunol. 2015:136(4):914-22.

21. Pocock SJ, Simon R. Sequential treatment assignment with balancing for prognostic factors in the controlled clinical trial. Biometrics. 1975; 31(1):103-15

22. Huss-Marp J, Kramer U, Eberlein B, Pfab F, Ring J, Behrendt H, et al. Reduced exhaled nitric oxide values in children with asthma after inpatient rehabilitation at high altitude. J Allergy Clin Immunol. 2007;120(2):471-2.

23. Nici L, Donner C, Wouters E, Zuwallack R, Ambrosino N, Bourbeau J, et al. American Thoracic Society/European Respiratory Society statement on pulmonary rehabilitation. Am J Respir Crit Care Med. 2006;173(12):1390-413.

24. Trevor JL, Bhatt SP, Wells JM, Kirkpatrick d SC, Hitchcock J, et al. Benefits of completing pulmonary rehabilitation in patients with asthma. J Asthma. 2015;52(9):969-73.

25. Renolleau-Courtois D, Lamouroux-Delay A, Delpierre S, Badier M, LagierTessonnier F, Palot A, et al. Home-based respiratory rehabilitation in adult patients with moderate or severe persistent asthma. J Asthma. 2014:51(5): $552-8$.

26. Carson KV, Chandratilleke MG, Picot J, Brinn MP, Esterman AJ, Smith BJ. Physical training for asthma. Cochrane Database Syst Rev. 2013;9:CD001116.

27. Boyd A, Yang CT, Estell K, Ms CT, Gerald LB, Dransfield M, et al. Feasibility of exercising adults with asthma: a randomized pilot study. Allergy Asthma Clin Immunol. 2012;8(1):13.

28. Constantini K, Wilhite DP, Chapman RF. A clinician guide to altitude training for optimal endurance exercise performance at sea level. High Alt Med Biol. 2017:18(2):93-101.

\section{Publisher's Note}

Springer Nature remains neutral with regard to jurisdictional claims in published maps and institutional affiliations.

Ready to submit your research? Choose BMC and benefit from:

- fast, convenient online submission

- thorough peer review by experienced researchers in your field

- rapid publication on acceptance

- support for research data, including large and complex data types

- gold Open Access which fosters wider collaboration and increased citations

- maximum visibility for your research: over $100 \mathrm{M}$ website views per year

At BMC, research is always in progress.

Learn more biomedcentral.com/submissions 